\title{
Infodemia, desinformação e vacinas: a circulação de conteúdos em redes sociais antes e depois da COVID-19
}

\author{
Infodemic, disinformation and vaccines: the circulation of content \\ on social networks before and after COVID-19
}

Luisa Medeiros Massarani a

Tatiane Leal a (iD)

Igor Waltz a, b (D)

Amanda Medeiros a (D)

\begin{abstract}
RESUMO: A pandemia da COVID-19 está sendo acompanhada pela circulação de um grande volume de informações, em parte enganosas ou falsas, fenômeno conhecido como "infodemia". A superabundância informativa dificulta a identificação de fontes confiáveis e pode afetar a adesão a medidas de contenção, como as vacinas. Neste artigo, investigamos os cem links sobre "vacina" que geraram mais engajamento nas redes sociais em 2020 e os comparamos com os de mais engajamento em 2018-2019, antes da pandemia. O objetivo é compreender os modos como a infodemia afeta o debate público sobre vacinação, como a desinformação aparece nessas conversações e quais são os posicionamentos, emissores e temas privilegiados. Identificamos que o engajamento médio aumentou 8,6 vezes e que a predominância de informações verificadas se manteve antes e durante a pandemia. Contudo, o engajamento da desinformação cresceu de maneira expressiva e seu perfil mudou: se em 2018-2019 predominavam os conteúdos totalmente falsos e emitidos por veículos não profissionais, em 2020 se destacam as informações distorcidas por manchetes sensacionalistas emitidas por veículos profissionais. Além disso, a instrumentalização política do debate sobre vacinação, presente nos dois contextos, chama a atenção para a relação entre desinformação e disputas narrativas. Esses resultados apontam a complexificação da infodemia e a necessidade de estratégias de combate à desinformação que levem em consideração os contextos econômicos e sociopolíticos da circulação de informações nas redes.
\end{abstract}

Palavras-chave: Infodemia; Vacina; Desinformação; Redes Sociais; COVID-19.

ABSTRACT: The COVID-19 pandemic is being accompanied by the circulation of a large volume of information, partly misleading or false, a phenomenon known as "infodemic". The profusion of information makes it difficult to identify reliable sources and can affect adherence to containment measures, such as vaccines. In this article, we investigated the 100 links about vaccines that generated the highest engagement on social media in 2020 and compared them with those with the highest engagement in 2018-2019, before the pandemic. The objective is to understand how infodemic affects the public debate on vaccination, how disinformation appears in these conversations, and what are the positions, emitters, and privileged themes. We found that the average engagement increased by 8.6 times and that the predominance of verified information remained before and during the pandemic. However, the engagement of disinformation has grown significantly and its profile has changed: if the false content, emitted by non-professional vehicles, predominated in 2018-2019, the information distorted by sensationalized headlines emitted by professional vehicles stands out in 2020. Besides, the political instrumentalization of the debate on vaccination, present in both contexts, draws attention to the

a Instituto Nacional de Comunicação Pública da Ciência e Tecnologia, Fundação Oswaldo Cruz, Rio de Janeiro, RJ, Brasil.

b Programa de Pós-graduação em Ensino em Biociências e Saúde, Instituto Oswaldo Cruz, Fundação Oswaldo Cruz, Rio de Janeiro, RJ, Brasil.

* Correspondência para/Correspondence to: Luisa Medeiros Massarani. Endereço: Instituto Nacional de Comunicação Pública de Ciência e Tecnologia (INCT-CPCT) - Prédio da Expansão Fiocruz - Av. Brasil, 4036, 40 andar, sala 414, Manguinhos, CEP: 21040-361, Rio de Janeiro, Brasil. E-mail: luisa.massarani8@gmail.com.

Recebido em/Received: 07/04/2021; Aprovado em/Approved: 16/06/2021.

Artigo publicado em acesso aberto sob licença CC BY 4.0 Internacional $@()$ 
relationship between disinformation and narrative disputes. These results point to the infodemic complexity and the need for strategies to combat disinformation that take into account the economic and socio-political contexts of the informative circulation on the networks.

Keywords: Infodemic; Vaccine; Disinformation; Social networks; COVID-19.

\section{INTRODUÇÃO}

A emergência global do SARS-CoV-2 em 2020 deflagrou não apenas uma crise política, socioeconômica e de saúde pública, mas também um significativo quadro de desordem informacional, marcado por disputas de narrativa e dispersão de informações falsas. Nesse cenário, cientistas, jornalistas e profissionais da informação têm trabalhado para mitigar os efeitos da desinformação e fornecer à população informações baseadas em evidências científicas. Essa atuação se torna especialmente crítica em um quadro de “infodemia”, uma produção e circulação de informações em larga escala, em um curto período de tempo, sobre um mesmo assunto, incluindo-se rumores, informações incorretas e notícias falsas (OMS 2018).

Ainda que não tenha se consolidado plenamente como um conceito formal, a noção de infodemia já esteve atrelada a epidemias anteriores (OMS 2019). A rápida e intensa dispersão de informações, potencializada pelo uso de redes sociais e dispositivos móveis, pode dificultar a identificação de informações confiáveis, impactando a percepção dos riscos e gerando relutância de parte da população em adotar medidas de contenção (OMS 2018). Esse cenário constitui um terreno fértil para informações falsas sobre a origem do vírus, formas de contágio, medidas de prevenção e contenção, número de casos e mortes e, inclusive, sobre as vacinas.

A dispersão de notícias falsas que desqualificam a eficácia e a segurança dessas aplicações é um fenômeno já observado antes da pandemia. Em pesquisa com os cem links sobre vacinas de maior engajamento nas redes sociais entre 2018 e 2019, identificamos que as informações falsas ou distorcidas representaram $13,5 \%$ da amostra. Em sua maioria, tais discursos revelaram visão contrária às vacinas, propagando supostos efeitos colaterais ou denunciando a negligência das autoridades frente ao "risco" da vacinação (Massarani et al. 2020a).

Tais disputas de sentido acabam por gerar desdobramentos sobre a forma como segmentos da população reconhecem a vacinação. Estudos têm demonstrado um crescimento da hesitação vacinal, isto é, indivíduos que recusam ou postergam sua imunização e de seus filhos por incerteza ou falta de confiança (Kennedy 2020). Além disso, movimentos antivacina têm conquistado espaço nas redes, ancorados em teorias conspiratórias que distorcem estudos científicos e propagam informações falsas (Katta 2012). Nesse panorama, observa-se quedas nas taxas de cobertura vacinal em diversos países. No Brasil, o Programa Nacional de Imunizações (PNI) vem registrando retração nas coberturas desde 2015 (Zorzetto 2018) e, ainda que se possa atribuir isso a diversos fatores, o papel da desinformação não pode ser subestimado.

A hesitação vacinal é especialmente grave no contexto da pandemia, no qual diversas autoridades, incluindo o Presidente da República, fizeram uso das redes para minimizar 
a gravidade da doença, atacar medidas de distanciamento e pôr em dúvida a segurança das vacinas. Isso se refletiu em um desinteresse do governo federal na aquisição de vacinas e na ausência de uma coordenação nacional para imunizar a população, além da escalada de casos e do colapso no sistema de saúde. Apesar de o Brasil contar com experiência técnica de distribuição de vacinas, a imunização contra a COVID-19 tem sido marcada pela lentidão, escassez e desarticulação (Paula et al. 2021) - pelo menos até 28 de março de 2021 , quando $6,5 \%$ da população brasileira tinha recebido sua primeira dose e $1,9 \%$ a segunda dose 1 .

Diante desse quadro, nosso objetivo geral é compreender os modos como a infodemia impacta a circulação de informações sobre vacinas nas redes. Para isso, analisamos os cem links sobre vacinas de maior engajamento nas redes sociais em 2020, e comparamos esse corpus com o de nossa pesquisa anterior, as cem URLs de maior engajamento durante o período de 2018-2019. Nossos objetivos específicos são investigar de que forma a desinformação se apresenta nessas conversações e identificar quais as temáticas, emissores e posicionamentos são privilegiados pelos interagentes brasileiros antes e durante a pandemia. Em um momento em que a vacinação assume centralidade nas discussões da esfera pública midiatizada, mapear os contornos do debate público sobre vacinas nas redes sociais pode amparar estratégias para combater a desinformação e a hesitação vacinal.

\section{INFODEMIA, DESINFORMAÇÃO E REDES SOCIAIS}

A noção de "infodemia" tem conquistado atenção crescente no contexto da saúde pública, especialmente na gestão de epidemias. O termo já foi empregado anteriormente pela Organização Mundial da Saúde (OMS) para designar a superabundância de informações associada a surtos virais, como os de SARS em 2003, H1N1 em 2009, e MERS em 2012 (OMS 2018). Contudo, embora tenham gerado apreensão entre a população e facilitado a dispersão de informações em desacordo com as evidências científicas, tais eventos anteriores não obtiveram a mesma dimensão observada durante a pandemia da COVID-19 (Hernández 2020). A infodemia, portanto, deve ser entendida como um complexo fenômeno atrelado a um contexto de crise sanitária, e influenciado pela popularização de tecnologias da comunicação, que radicalizam a instantaneidade e a abrangência internacional da distribuição de (des)informação (OMS 2018; 2019).

Especialmente durante a atual pandemia da COVID-19, a sobrecarga informativa associada à infodemia constitui uma ameaça à saúde pública, pois pode comprometer a adesão das pessoas às medidas de contenção (Cinelli et al. 2020). Essa abundância de informações pode agravar o contexto prévio de "desordem informativa" (Wardle, Derakhshan 2017), isto é, um ambiente informacional marcado pela disseminação crescente de discursos radicalizados, teorias conspiratórias e notícias falsas. Nesse

\footnotetext{
${ }^{1}$ Disponível em

https://viz.saude.gov.br/extensions/DEMAS_C19Vacina/DEMAS_C19Vacina.html. Acesso em 29 mar. 2021.
} 
cenário de desordem, a disseminação deliberada de conteúdos falsos por atores malintencionados convive com o compartilhamento de informações fora de contexto, distorcidas ou enganosas por pessoas que as julgam verdadeiras. A partir da proposição dos autores, compreendemos desinformação como a dispersão de informações falsas, distorcidas ou manipuladas, de modo intencional ou não, que teria como consequência a distorção do debate público, gerando danos a indivíduos ou grupos sociais.

No contexto da COVID-19, os conteúdos falsos nas redes sociais brasileiras incluem desde métodos caseiros para prevenir e curar a doença até o suposto uso do vírus como estratégia política (Galhardi et al. 2020). Além disso, o Brasil é um dos únicos países em que ainda persiste a desinformação sobre o uso de ivermectina e cloroquina para o tratamento da COVID-19, substâncias cujo uso foi incentivado inclusive por atores políticos (Machado et al. 2020). A desinformação, portanto, deriva de práticas sociais inseridas em um cenário cultural de disputas de sentidos, revelando, muitas vezes, mais aspectos políticos do que de saúde (Oliveira 2020). Por exemplo, a respeito dos debates sobre hidroxicloroquina nas redes digitais, Araujo e Oliveira (2020) identificaram que as discussões giraram em torno de ataques e apoio a agentes políticos, pressão pela adoção da droga no sistema de saúde, manifestações de descrença em relação à ciência e à mídia, além da apropriação de jargões e figuras científicas para reafirmar os vieses de crenças a favor e contra a medicação.

Outro problema que agrava a desordem informativa é a atual configuração da economia da atenção nas redes sociais, que se tornam um dos principais espaços de consumo de informações ${ }^{2}$. Em muitas ocasiões, os conteúdos são curtidos, comentados e compartilhados sem a plena leitura, o que dificulta a compreensão (Zago, Silva 2014). Além disso, a atenção dos consumidores nas redes se torna alvo da competição acirrada entre produtores de conteúdo, incluindo veículos jornalísticos. A disputa por audiência e, consequentemente, aportes publicitários pode gerar matérias de baixa relevância e títulos apelativos e distorcidos (Vieira, Christofoletti 2015).

Desse modo, a infodemia e a desinformação são profundamente influenciadas pelas lógicas político-econômicas das plataformas digitais. Ao assumirem o papel central na infomediação, essas plataformas adotam sistemas de governança, como os protocolos de interação - curtir, seguir, compartilhar, avaliar - e a classificação algorítmica (Poell et al. 2020). Essa última controla a visibilidade de conteúdos por meio de uma filtragem automatizada que reconhece padrões e conexões dos usuários. Essa ação algorítmica, combinada à mediação humana, contribui para a formação de "bolhas informacionais", sistemas de retroalimentação em que informações são filtradas e compartilhadas de modo a apoiar narrativas em particular, limitando o contato dos interagentes a outros pontos de vista (Pariser 2012; Recuero et al. 2020). No entanto, não é possível reduzir a crítica à infraestrutura das redes, sendo necessário levar em

\footnotetext{
${ }^{2}$ De acordo com o Digital News Report 2020, do Instituto Reuters/Universidade de Oxford, o consumo de notícias em mídias sociais ultrapassou a televisão no Brasil: $67 \%$ dos entrevistados declararam se informar pelas redes sociais, enquanto $66 \%$ se informam pela TV. Disponível em: https://www.digitalnewsreport.org/survey/2020/. Acesso em 15 mar. 2021.
} 
conta o contexto político de ataques sistemáticos às instituições democráticas e de dispersão de discursos intolerantes (Oliveira 2020).

No debate público sobre ciência e saúde, a desinformação se dissemina em meio à persistência de crenças não compatíveis com as evidências científicas, um processo agravado por um contexto de polarização em que a ciência é muitas vezes refutada a partir de ideologias particulares (Castelfranchi 2019; Scheufele, Krause 2019). Durante a pandemia, disputas de sentido no Brasil em torno do combate à COVID-19 mobilizaram a agenda política, polarizada de um lado em uma retórica a favor da retomada imediata da economia e do uso de medicações sem comprovação, e de outro, em favor de medidas baseadas em evidências científicas, como o distanciamento social, o uso de máscaras e a vacinação (Monari et al. 2020).

Portanto, como observamos a partir dessa breve revisão, a infodemia se caracteriza como um fenômeno complexo e multifacetado. Nesse artigo, inspirados na proposição da OMS $(2018 ; 2019)$, assumimos uma compreensão de infodemia como um fenômeno comunicacional atrelado ao contexto de crise de saúde pública, que afeta a produção e a circulação das informações em saúde. Diante do atual quadro infodêmico associado à COVID-19, investigar os debates públicos em ciência e saúde nas redes se torna um importante passo para compreender como a superabundância de informações pode influenciar os modos como os públicos se apropriam desses conteúdos. Mais especificamente sobre as vacinas, a principal aposta da comunidade científica para superarmos a pandemia, é essencial compreender quais as temáticas, posicionamentos e emissores são privilegiados, assim como o papel da desinformação nesse quadro.

\section{MÉTODOS}

A metodologia deste estudo apresentou três etapas: 1) a coleta do corpus; 2) a análise a partir de cinco categorias; e 3) a comparação dos resultados com os dados de 20182019 (Massarani et al. 2020a). Para viabilizar a primeira etapa, utilizamos o BuzzSumo3, uma ferramenta de monitoramento que permite aferir que conteúdos sobre determinado tema geraram mais engajamento em redes sociais. Essa plataforma tem sido utilizada em pesquisas científicas que investigam a circulação de desinformação em mídias sociais (Allcott et al. 2019; Allcott, Gentzkow 2017), inclusive na área da saúde (Alsyouf et al. 2019; Sommariva et al. 2018; Waszak et al. 2018), por viabilizar um recorte possível sobre os contornos do debate público nas redes sociais.

Em nossa amostra inicial, coletamos os cem links — máximo permitido pela ferramenta -, contendo a palavra-chave "vacina" que geraram mais engajamento nessas redes sociais entre 01 de janeiro e 31 de dezembro de 2020, ano em que eclodiu a pandemia de COVID-19. Como nosso objetivo era avaliar o debate público brasileiro, selecionamos apenas publicações em língua portuguesa e excluímos da amostra cinco links de

\footnotetext{
${ }^{3}$ Disponível em https://buzzsumo.com/. Acesso em: 12 mar. 2021.
} 
veículos de Portugal, além de um link "quebrado". A amostra válida, portanto, consistiu em 94 links.

O BuzzSumo considera como métricas quantificáveis de engajamento a soma dos compartilhamentos, comentários, curtidas e reações que um link obteve no Facebook, Twitter, Pinterest e Reddit. Por mais que o uso da ferramenta esteja condicionado a uma definição de engajamento restrita aos protocolos das redes sociais, como curtir, comentar e compartilhar, esses critérios se constituem como uma métrica possível para identificar conteúdos que alcançaram mais atenção nos espaços digitais. No contexto das mídias sociais, em que os significados são negociados e partilhados entre os interagentes, a confiabilidade de um conteúdo não está atrelada apenas à qualidade das informações, mas também a processos de socialização em torno dele (Tandoc Jr. et al 2017). Além disso, quanto maior o engajamento, mais a visibilidade de um conteúdo é impulsionada por ação algorítmica nas redes (Kischinhevsky, Fraga 2020).

Na segunda etapa, definimos cinco categorias de análise: a) engajamento; b) tema; c) acurácia; d) posicionamento; e) tipo de veículo. Essas categorias foram desenvolvidas e aperfeiçoadas em pesquisas anteriores sobre os debates públicos em ciência e saúde nas redes sociais (Massarani et al. 2020a; 2020b), a partir de contribuições teóricometodológicas de estudos nas áreas da comunicação e da divulgação da ciência. Essa proposta de metodologia objetiva atender aos propósitos desta investigação, observando contornos das discussões públicas em torno das vacinas. De tal modo, é possível verificar não apenas quais os conteúdos com mais engajamento nas redes sociais, mas também avaliar a qualidade da informação presente neles, as principais fontes emissoras e os principais posicionamentos tomados em um espaço atravessado por disputas de sentido.

A categoria engajamento avalia quantitativamente a interação gerada por cada link. Consideramos aqui o que o BuzzSumo define como "engajamento total", ou a soma de compartilhamentos, comentários, curtidas e reações no Facebook, de compartilhamentos no Twitter, de compartilhamentos e comentários no Reddit e de compartilhamentos no Pinterest. Já a categoria tema combinou a discussão qualitativa dos assuntos abordados e a identificação quantitativa das vacinas citadas. Inferindo a predominância da temática da pandemia em 2020, avaliamos também que vacinas contra COVID-19 foram abordadas.

Na categoria acurácia, avaliamos a precisão das informações, de modo a investigar a presença da desinformação. Para isso, apuramos qualitativamente as informações citadas, comparando-as com dados de artigos científicos, fontes oficiais e outros veículos jornalísticos. Em seguida, utilizamos a seguinte categorização, inspirada na proposta de Wardle e Derakhshan (2017), para classificar os diferentes tipos de desinformação (Quadro 1).

Quadro 1. Classificação da acurácia.

Conteúdo verificado
Informação verificável a partir de fontes oficiais, científicas e/ou jornalísticas 


\begin{tabular}{|l|l|l|}
\hline \multicolumn{1}{|l|}{ Conteúdo não verificável } & $\begin{array}{l}\text { Informações não possíveis de serem comparadas, } \\
\text { como opiniões pessoais, enquetes públicas e } \\
\text { conteúdos ficcionais }\end{array}$ \\
\hline \multirow{2}{*}{ Desinformação } & Conteúdo enganoso & $\begin{array}{l}\text { Uso enganoso de uma informação para enquadrar } \\
\text { uma questão ou um indivíduo }\end{array}$ \\
\cline { 2 - 3 } & Conteúdo fabricado & $\begin{array}{l}\text { Conteúdo genuíno editado ou manipulado para } \\
\text { enganar } \\
\text { prejudicar }\end{array}$ \\
\cline { 2 - 3 } & Contexto falso & $\begin{array}{l}\text { Conteúdo genuíno, compartilhado junto a uma } \\
\text { informação contextual falsa (ex.: localização, } \\
\text { data, etc) }\end{array}$ \\
\cline { 2 - 3 } & Paródia ou sátira & $\begin{array}{l}\text { Títulos, manchetes enganar ou elementos visuais } \\
\text { contradizem o conteúdo }\end{array}$ \\
\hline
\end{tabular}

Fonte: Elaboração dos autores a partir de Wardle e Derakhshan (2017).

Em posicionamento, avaliamos se os conteúdos adotam postura pró-vacina, neutra ou contrária à imunização. Consideramos pró-vacina conteúdos que partem do pressuposto e/ou defendem ativamente que as vacinas são seguras, eficazes e necessárias. Já os conteúdos contra a vacina partem do pressuposto e/ou defendem ativamente que as vacinas são inseguras, ineficazes e desnecessárias. Os conteúdos neutros, por sua vez, não assumem claramente um desses lados.

Por fim, em tipo de veículo, analisamos os emissores responsáveis pelos URLs, classificando-os entre profissionais e não profissionais. Inspirados nos critérios de Mendonça e Pereira Neto (2015) e Silva et al. (2017) para avaliar a confiabilidade de fontes de informação em saúde, consideramos os seguintes aspectos para classificar um veículo como profissional: política editorial definida; indicação de empresa/instituição responsável pelo veículo; identificação de autores e da equipe editorial; citação de fontes para as informações. Avaliamos qualitativamente os sites e páginas de redes sociais dos veículos e aqueles que não forneceram essas informações foram considerados não profissionais.

Essa categoria leva em consideração a crescente complexidade do ecossistema midiático, aqui compreendido como o intricado sistema de relações entre os meios massivos e digitais, que se influenciam mutuamente e são afetados por dinâmicas emergentes, como a mobilidade e a crescente individualização da produção e do consumo (Canavilhas 2011). De tal modo, os descentramentos trazidos pelas tecnologias digitais tornaram as fronteiras do campo midiático mais porosas à chegada de novos atores sociais, o que potencializa a pluralidade de vozes e abordagens no 
campo da mídia, ao passo que também abre caminho à produção e dispersão de conteúdos danosos e desinformativos (Waltz 2019).

Portanto, sem o objetivo de estabelecer uma dicotomia entre esses atores, a classificação entre veículos profissionais e não profissionais buscou esquadrinhar um ecossistema midiático plural em que veículos de empresas de comunicação e iniciativas lideradas por profissionais de jornalismo cada vez mais convivem com projetos individuais de comunicadores não profissionais. Buscamos, ainda, avaliar a presença da desinformação entre os conteúdos emitidos por esses veículos.

Na terceira etapa, comparamos esses resultados referentes a 2020 aos obtidos a partir da análise do corpus 2018-2019. Naquela ocasião, foram utilizados os mesmos filtros de pesquisa no BuzzSumo para o período de 22 de maio de 2018 a 21 de maio de 2019, gerando uma amostra válida de 89 links (Massarani et al. 2020a). Para viabilizar a comparação, mantivemos as quatro categorias de análise - tema, acurácia, posicionamento e tipo de veículo - e fizemos duas adições: a análise do engajamento e a complexificação da categoria acurácia ${ }^{4}$ inspirada em Wardle e Deraksham (2017). A partir desse contraste entre o contexto de antes e durante a pandemia, avaliamos possíveis consequências da infodemia para o ambiente informacional das redes sociais no que diz respeito ao consumo e ao compartilhamento de informações sobre a vacinação.

\section{RESULTADOS}

A análise e comparação dos resultados mostrou continuidades e rupturas importantes na circulação de conteúdos sobre vacinas em redes sociais. Em relação ao engajamento, houve um aumento de 8,6 vezes da média de engajamento por link em 2020 (Tabela 1).

Tabela 1. Engajamento dos links em 2018-2019 e em 2020.

\begin{tabular}{ccc}
\hline & Engajamento total & Média de Engajamento por link \\
\hline $\mathbf{2 0 1 8 - 2 0 1 9}$ & 3.685 .100 & 41.405 \\
$\mathbf{2 0 2 0}$ & 33.306 .200 & 354.321 \\
\hline
\end{tabular}

Fonte: Elaboração dos autores.

A maior concentração de engajamento na conversação sobre vacinas em 2020 ocorreu entre maio, junho e julho, com o pico nesse último mês (Figura 1). Os links compartilhados em julho se referem, principalmente, a resultados positivos na fase de testes obtidos por vacinas contra a COVID-19. Nos meses seguintes, o engajamento em relação às vacinas não voltou a ultrapassar o patamar verificado em abril.

\footnotetext{
${ }^{4}$ Substituímos veracidade (Massarani et al. 2020a) por acurácia após adotar a perspectiva de Wardle e Deraksham (2017) para a análise da desinformação.
} 
Figura 1. Distribuição mensal do engajamento em torno de conteúdos sobre vacina em 2020.

10000000

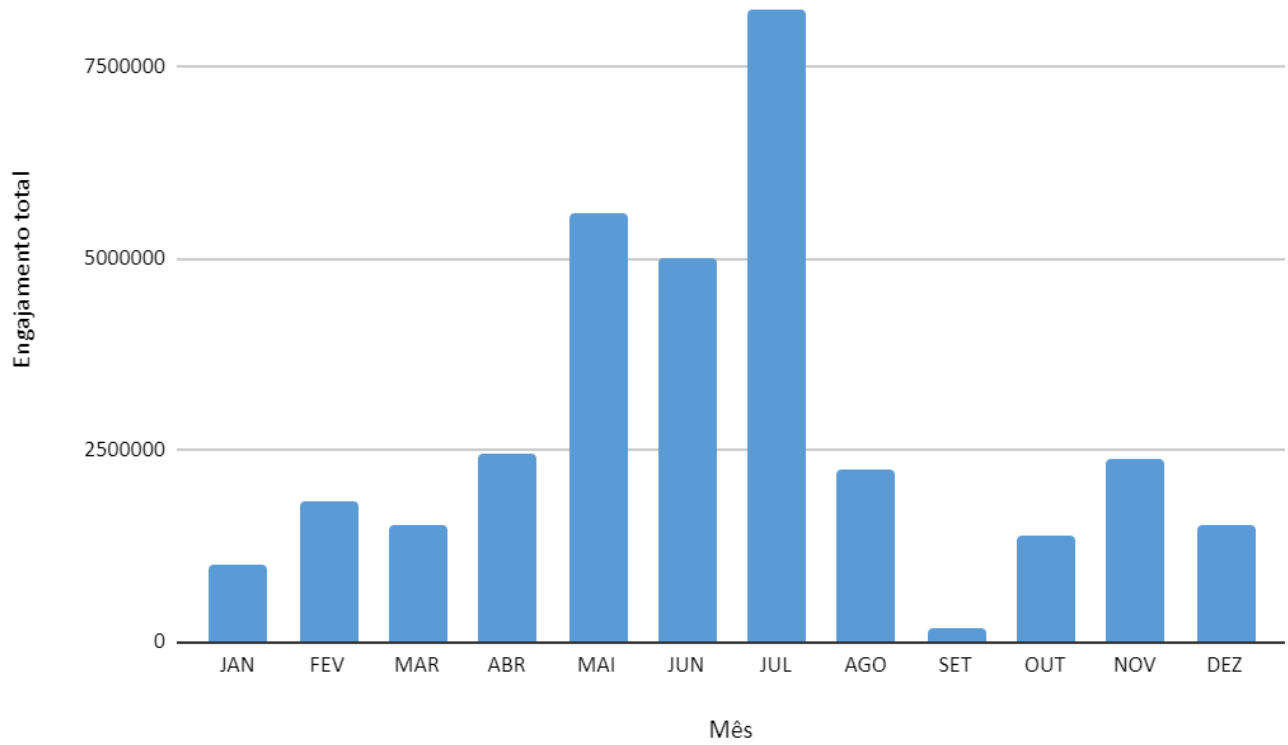

Fonte: Elaboração dos autores.

Já em 2018-2019, o pico de engajamento havia ocorrido em março de 2019, em torno da vacina contra meningite, por causa da morte do neto do ex-presidente Luiz Inácio Lula da Silva por suspeita da doença, o que foi descartado posteriormente. A causa da morte da criança foi identificada como sepse originada pela bactéria Staphylococcus aureus (Massarani et al. 2020a).

Como esperado, a COVID-19 foi o tema predominante em 91,5\% dos links de 2020. Conteúdos sobre câncer (4,3\%), Alzheimer (3,2\%) e HIV (1,1\%) foram publicados ou antes do início da pandemia no Brasil (janeiro e fevereiro) ou no fim do ano (novembro e dezembro). Ou seja, entre março e outubro a amostra se referiu totalmente à imunização contra COVID-19. Já em 2018-2019, foram abordadas vacinas para 25 doenças, com destaque para meningite, gripe, leishmaniose animal e febre amarela, além de HIV e câncer (Massarani et al. 2020a).

Ainda em relação aos temas, os conteúdos de 2020 versaram, principalmente, sobre o desenvolvimento das vacinas contra a COVID-19 e sobre a atuação dos governantes nos processos de compra e aplicação dos imunizantes. Esses resultados reverberam tendências já observadas em 2018-2019, quando as pesquisas para novos imunizantes e os debates políticos, com ênfase em campanhas de vacinação e políticas públicas, figuraram entre as principais temáticas (Massarani et al. 2020a).

A categoria posicionamento apresentou aumento do conteúdo pró-vacina (96,8\%), já predominante em 2018-2019 (86,7\%). O posicionamento contrário aparece em 2,1\% do corpus de 2020, enquanto em 2018-2019 representava 9,0\%. No contexto da pandemia, esses textos se posicionam contra um imunizante em específico, a Coronavac. $O$ 
posicionamento neutro, não verificado em 2018-2019, representa 1,1\% da amostra de 2020. Por fim, o uso metafórico da vacina (como em "Moro é a vacina para o câncer da corrupção, diz Onyx Lorenzoni”’5), que era de 3,4\% em 2018-2019, não ocorreu na amostra atual.

Figura 2. Comparação do posicionamento em relação à vacina em 2018-2019 e em 2020.

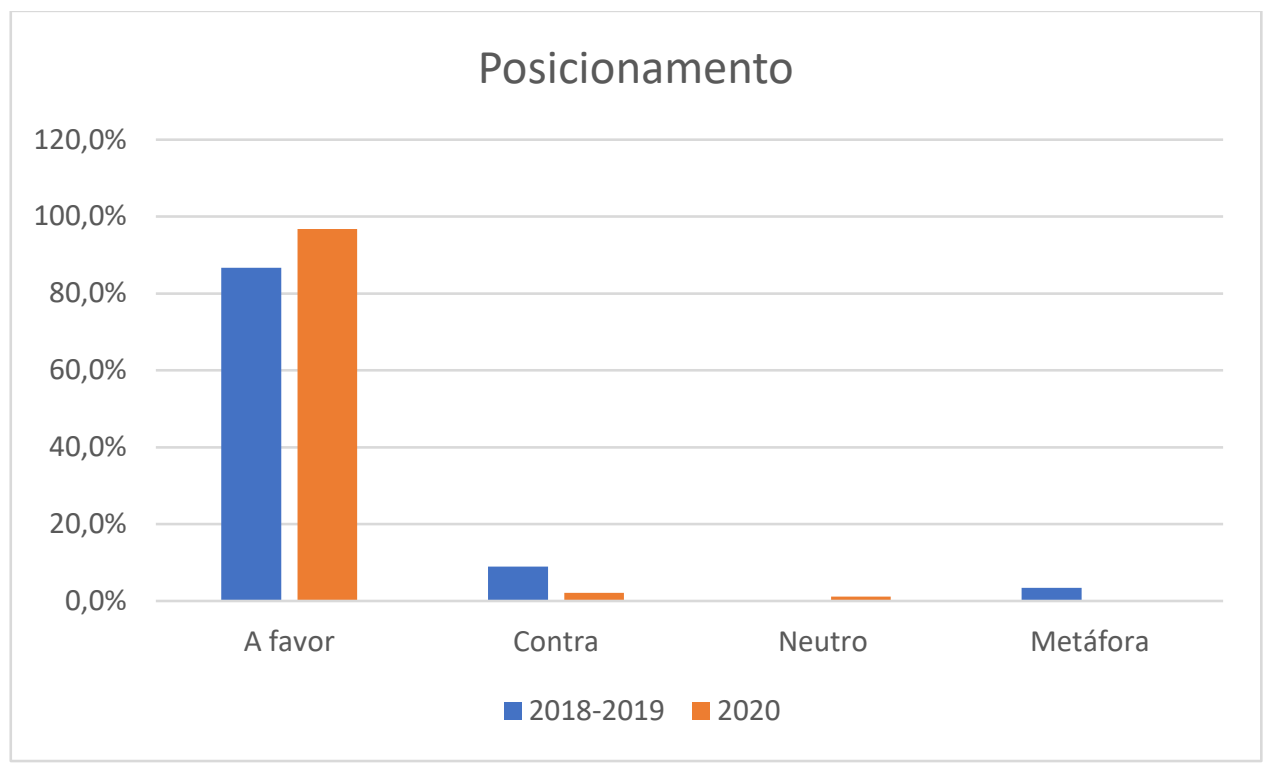

Fonte: Elaboração dos autores.

Em relação à acurácia, a proporção permanece praticamente a mesma: as informações verificadas representaram $80,9 \%$ da amostra de $2018-2019$ e $81,9 \%$ da de 2020 , enquanto a desinformação constituiu $13,5 \%$ do corpus de $2018-2019$ e $13,8 \%$ do de 2020 . O conteúdo não verificável passou de 5,6\% (2018-2019) para 4,3\% (2020).

Ao analisar os tipos de veículo, também verificamos uma continuidade entre os cenários. Predominam os emissores profissionais - de 74,2\% (2018-2019) para 74,5\% (2020) - sobre os não profissionais - de 24,8\% (2019-2019) para 24,5\% (2020). Em 20182019, encontramos 63 veículos, dos quais 45 eram profissionais. Entre eles, há 24 jornalísticos, dez sites de variedades, três blogs, três institucionais, dois especializados em fact-checking, dois de entretenimento e um de comércio eletrônico. $O$ emissor mais presente era o portal de notícias $G 1$ (10 links). Outros 18 veículos foram classificados como não profissionais. Já em 2020 foram identificados 41 veículos. Dos 24 profissionais, 19 são jornalísticos, quatro sites de variedades e um institucional. Os portais de notícias UOL (17 links) e G1 (15 links) são os dois maiores emissores. Outros 17 veículos são não profissionais.

Se a princípio a análise revelou continuidades entre o ecossistema informacional anterior e concomitante à pandemia, outros aspectos indicam importantes diferenças. $\mathrm{Na}$ amostra de 2020, os conteúdos desinformativos apresentam uma média de

5 Disponível em: https://noticias.r7.com/prisma/r7-planalto/moro-e-a-vacina-para-o-cancer-dacorrupcao-diz-onyx-lorenzoni-26042019. Acesso em 23 mar. 2021. 
engajamento por link maior do que a dos verificados: 412.223 contra 338.019. Essa relação não aparecia em 2018-2019, quando a desinformação tinha média de 36.200 e o conteúdo verificado, de 40.483 (Figura 3).

Figura 3. Comparação entre as médias de engajamento da informação verificada e da desinformação em 2018-2019 e 2020.

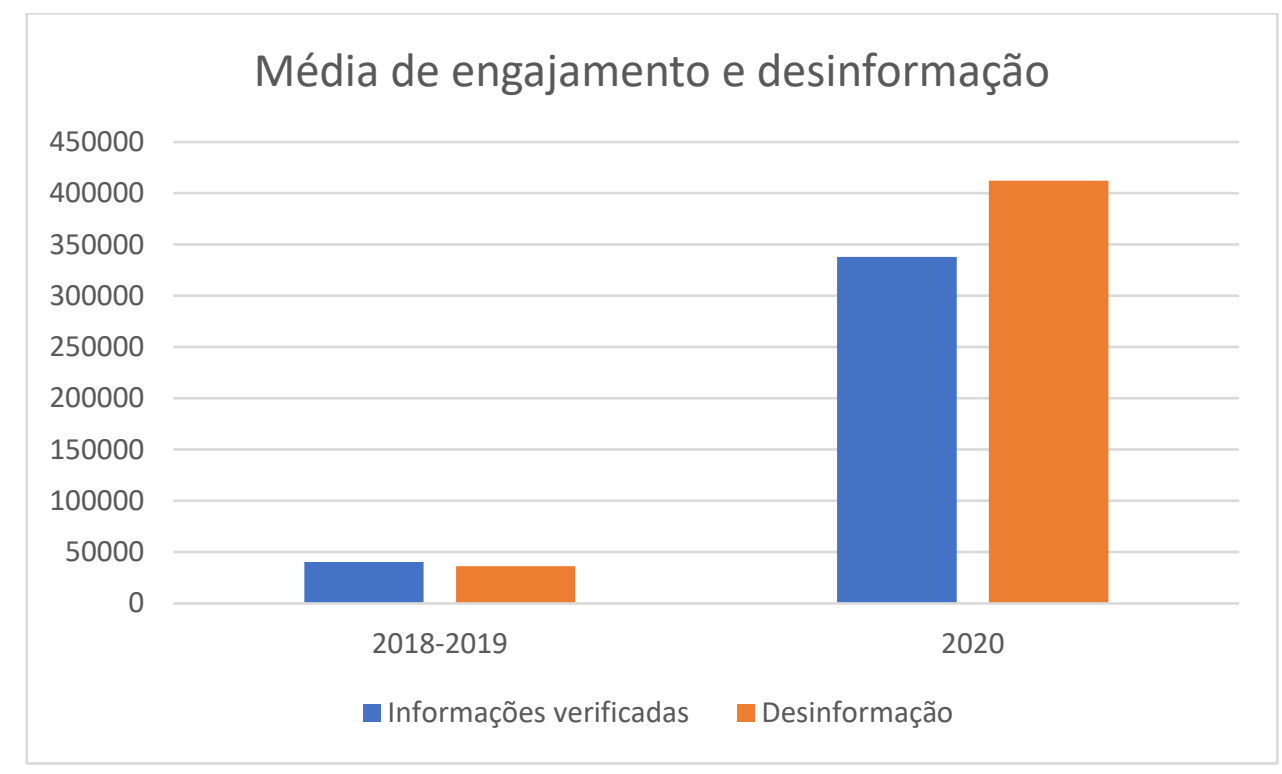

Fonte: Elaboração dos autores.

Além disso, o modo como a desinformação se apresentou teve mudanças consideráveis. Em 2018-2019, a maior parte da desinformação era composta por conteúdos fabricados (66,7\%), seguidos pelos conteúdos enganosos (25\%) e as conexões falsas (8,3\%). Na amostra de 2020 , são as conexões falsas $(84,6 \%$ que representam a maior parte do conteúdo desinformativo e o conteúdo fabricado diminui (15,4\%), ao passo que não foram encontrados conteúdos enganosos (Figura 4). Não foram identificados links classificados como conteúdo manipulado, contexto falso e paródia ou sátira em nenhuma das amostras. 
Figura 4. Comparação entre os tipos de desinformação encontrados em 2018-2019 e em 2020.

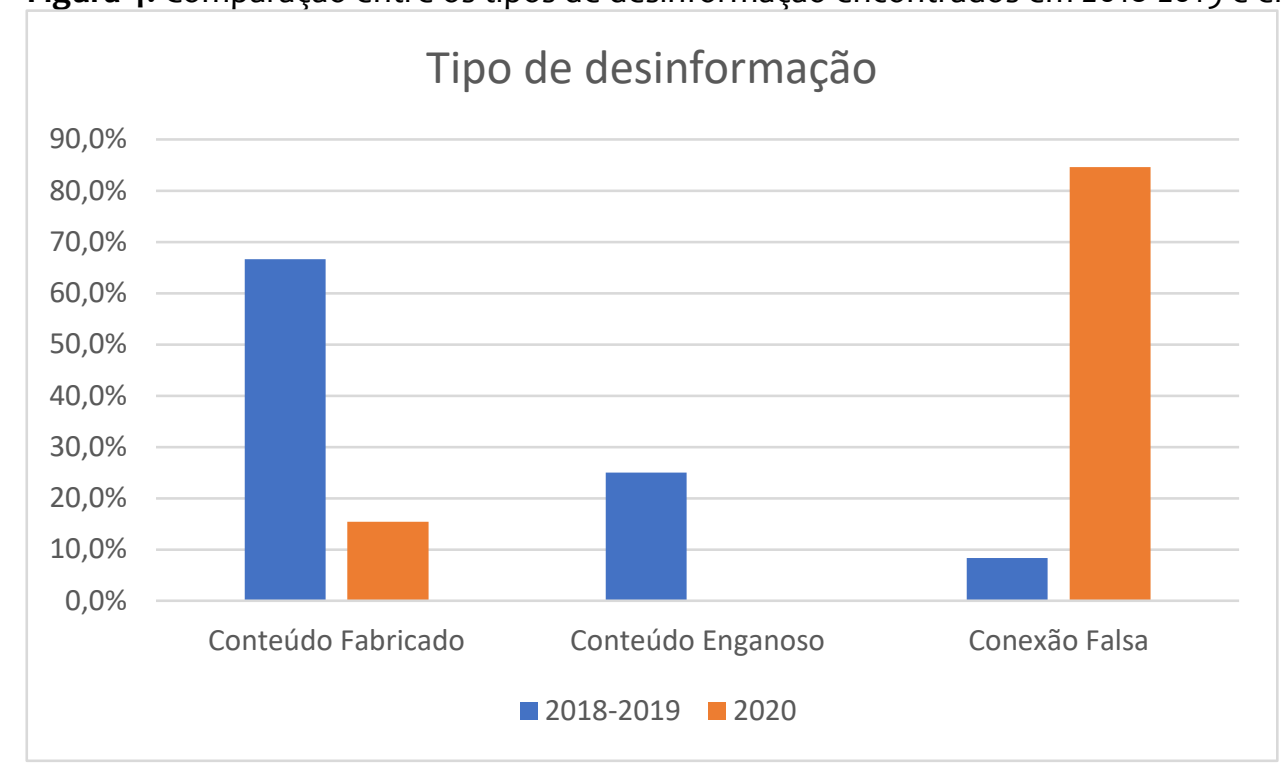

Fonte: Elaboração dos autores.

Além disso, enquanto em 2018-2019 a maior parte do conteúdo desinformativo foi produzido por veículos não profissionais (83,3\%), em 2020 esse cenário se inverte: são os veículos profissionais os principais responsáveis pela desinformação (61,5\%) (Figura 5):

Figura 5. Comparação entre os tipos de veículos responsáveis pela emissão de desinformação em 2018-2019 e 2020.

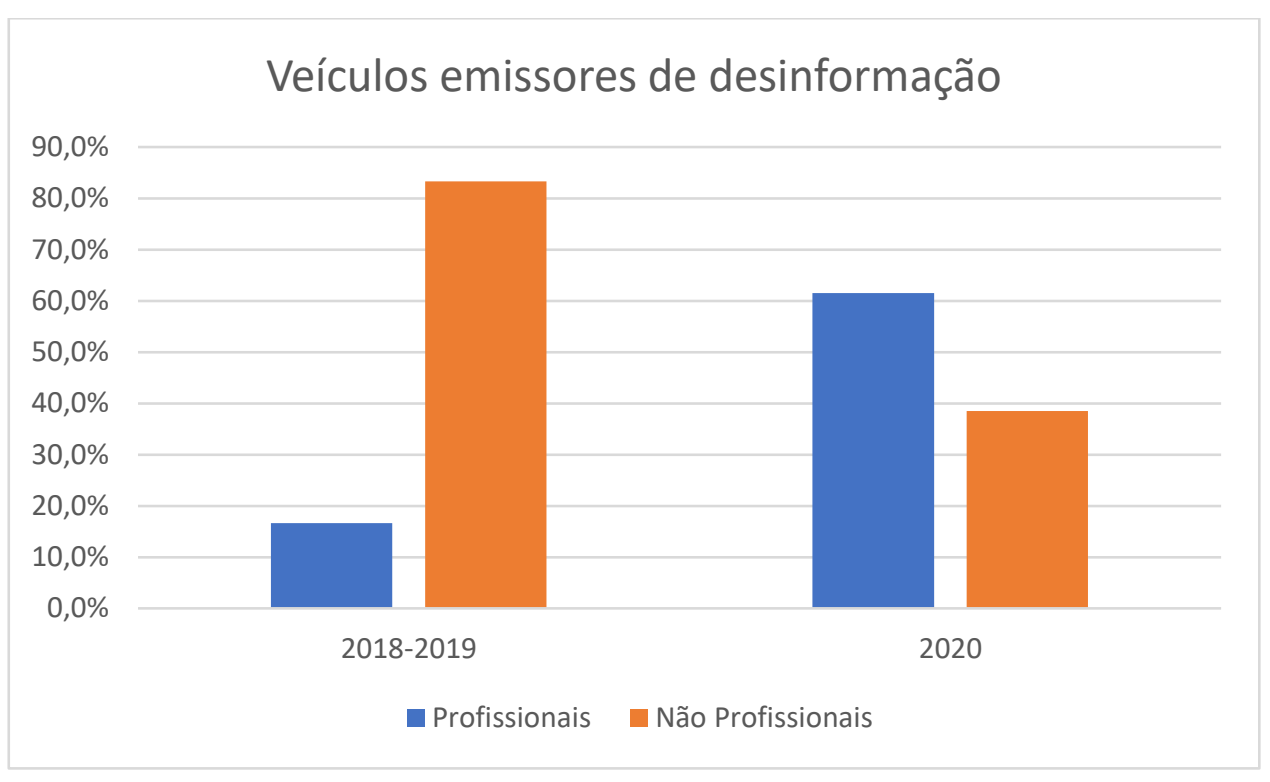

Fonte: Elaboração dos autores.

Quanto ao posicionamento dos conteúdos desinformativos, também encontramos uma descontinuidade: em 2018-2019, a maior parte da desinformação era contra a vacina, enquanto em 2020 ela é majoritariamente favorável à vacinação (Figura 6). 
Figura 6. Comparação do posicionamento da desinformação em 2018-2019 e 2020.

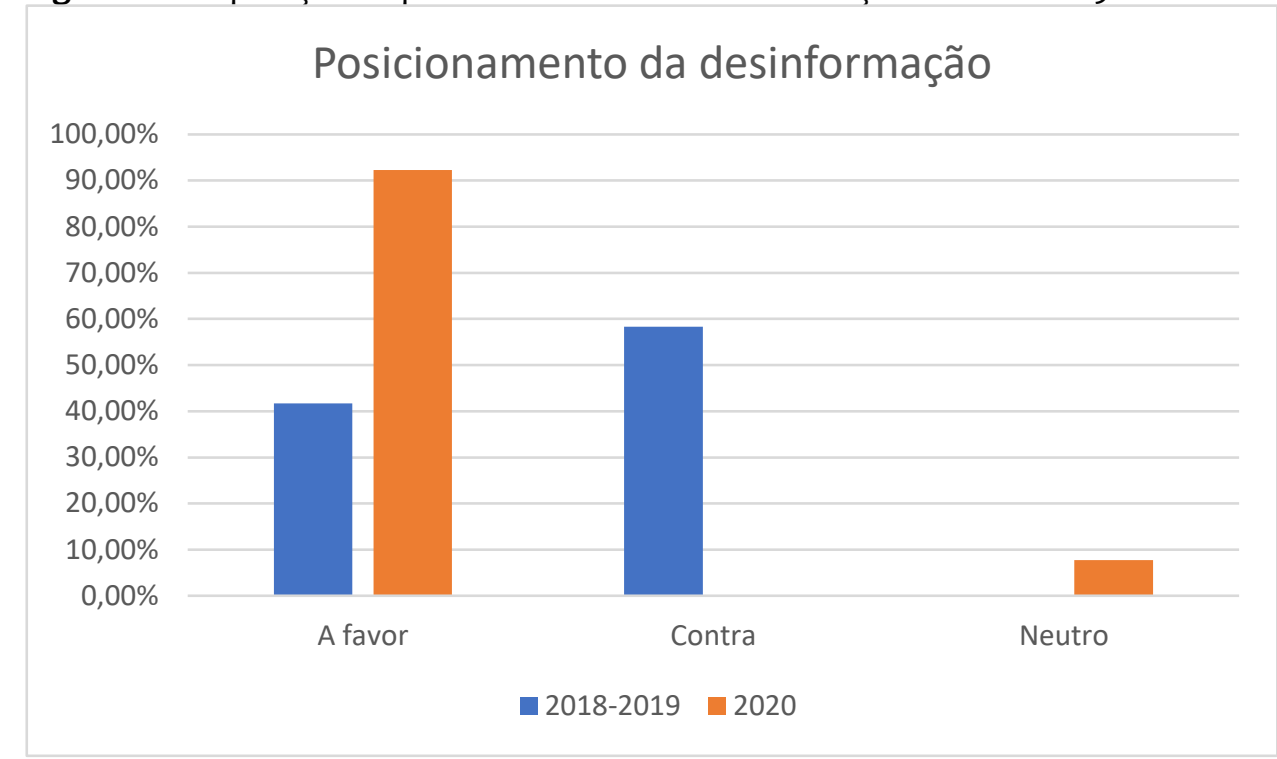

Fonte: Elaboração dos autores

Por fim, foram citadas dez vacinas contra a COVID-19 em 2020. A mais predominante é a de Oxford/Astrazeneca (20,2\%), seguida pela Coronavac $(18,1 \%)$ e pela imunização contra a doença de forma geral $(18,1 \%)$. As duas vacinas mais citadas foram as de laboratórios que possuem parcerias com instituições brasileiras - respectivamente, a Fundação Oswaldo Cruz (Fiocruz) e o Instituto Butantan - com acordos de transferência de tecnologia para a produção no Brasil. No momento da finalização deste artigo, apenas essas duas vacinas eram utilizadas na campanha de vacinação no país.

No entanto, ao levar em conta apenas o conteúdo desinformativo, a vacina mais citada é a Coronavac (23,1\%). A Sputnik V (15,4\%), quinto lugar entre o conteúdo geral, aparece no segundo lugar entre a desinformação, empatada com Oxford/Astrazeneca, Moderna e a imunização contra COVID-19 em geral. (Figura 7). Esses dados apontam para uma correlação entre vieses políticos e a circulação de desinformação sobre a COVID-19, conforme será discutido a seguir. 
Figura 7. Comparação entre a presença das vacinas contra COVID-19 na totalidade do corpus de 2020 e entre a desinformação.

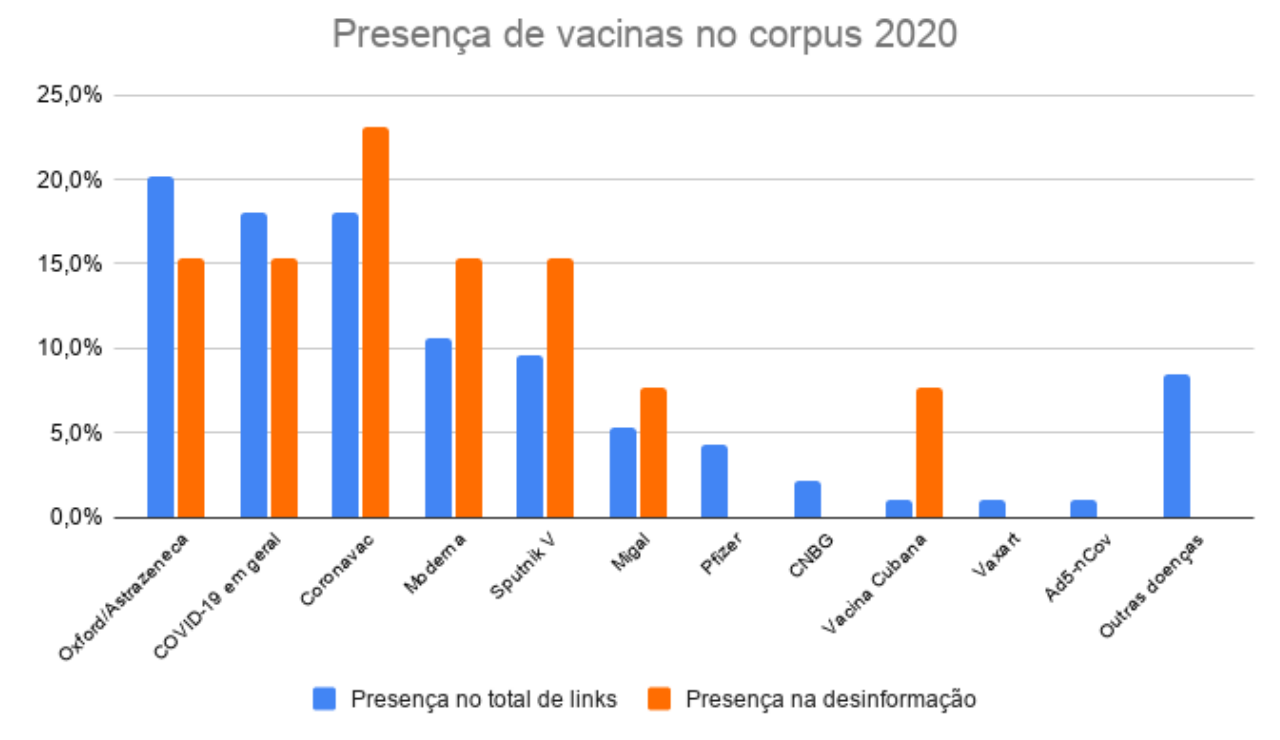

Fonte: Elaboração dos autores

\section{INSTRUMENTALIZAÇÃO POLÍTICA DO DEBATE SOBRE VACINAS}

O aumento de 8,6 vezes da média de engajamento dos links sobre vacina em 2020 confirma que a pandemia provocou um crescimento significativo da relevância da vacinação como tema de debate público. Além disso, com a forte predominância do posicionamento pró-vacina $(96,8 \%)$, observamos que a posição difundida por especialistas de que a vacinação é um dos instrumentos fundamentais para o controle da crise sanitária alcançou visibilidade nas redes. No entanto, após um pico no mês de julho, quando o país atravessava o patamar mais alto até então no número de mortos por COVID-19, o engajamento em torno da conversação sobre vacinas perde força e não retoma o patamar verificado em abril, ainda que uma nova alta de casos e mortes tenha ocorrido entre novembro e dezembro no país ${ }^{6}$. Nesses dois meses, inclusive, outras vacinas voltam a figurar entre os links de maior engajamento.

A predominância de uma só doença entre os links contrasta com o contexto prépandemia, em que vacinas contra 25 doenças despertaram o interesse público. No entanto, uma continuidade se estabelece entre os temas: a relação entre a política e vacinação. A morte do neto do ex-presidente Lula levou à instrumentalização política da discussão sobre a vacinação contra meningite, inclusive em espectros desinformativos. Enquanto alguns conteúdos propagaram a informação falsa de que Lula teria vetado a inclusão do imunizante na cesta de vacinas do Sistema Único de Saúde (SUS) em 2010, outros links se dedicaram à checagem dessa informação. $\mathrm{Na}$ verdade, Lula havia vetado um Projeto de Lei que previa a inclusão da vacina contra a

${ }^{6}$ Disponível em: https://covid19.who.int/region/amro/country/br. Acesso em 24 mar. 2021. 
meningite meningocócica $C$ (conjugada), uma vez que ela já estava contemplada no calendário de vacinação. A polarização política já marcava esse ambiente informativo, em títulos como "Lula vetou em 2010 vacina para meningite, doença que matou seu neto de 7 anos" (Hora 1 Rondônia) e "Bolsominions espalham fake news de que Lula teria vetado vacina; é mentira"8 (Plantão Brasil).

A relação entre agentes políticos e vacinação aparece também em "Trump afirma: a

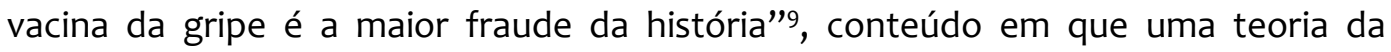
conspiração ganha legitimidade ao ser atribuída ao então presidente norte-americano (Massarani et al. 2020a). Ainda que, nesse caso, Trump não tenha feito essa afirmação, em diversos outros momentos o político fez declarações questionando a segurança e a eficácia das vacinas em suas redes sociais (Oliveira et al. 2020).

Portanto, o debate sobre vacinação na infodemia de COVID-19 ocorre em um ambiente informacional já anteriormente marcado pela instrumentalização política da ciência, pelo embate entre visões políticas polarizadas e pela reverberação de falas e ações de agentes políticos que contestam as posições defendidas por instituições científicas. Por um lado, a pandemia reforça a percepção de que a condução de uma crise sanitária depende dos agentes políticos. No corpus de 2020, a preocupação com a condução da pandemia pelo governo federal aparece em conteúdos como "Brasil fica de fora de ação mundial para acelerar vacina e apoiar OMS”"10 (UOL) e “"Já mandei cancelar', diz Bolsonaro sobre protocolo de intenções de vacina do Instituto Butantan em parceria com farmacêutica chinesa"11 (G1).

Por outro lado, a desconfiança em relação à Coronavac aponta para uma instrumentalização política do debate sobre vacinas. O imunizante do laboratório chinês Sinovac, apesar de não liderar as menções em geral, foi a vacina contra COVID19 mais citada por conteúdos desinformativos. Observamos que as dúvidas em relação à segurança e à eficácia desse imunizante não se apoiam em evidências científicas, e sim em questões políticas relacionadas a uma suposta falta de confiança na China. Isso se reforça pela escolha de se referir à Coronavac como "vacina chinesa", como em "Paulistas se recusam a tomar vacina da China contra Covid"12 (Pleno News).

Observamos ainda que a desordem informativa, no sentido proposto por Wardle e Derakhshan (2017), associada a essa instrumentalização política pode não se restringir

\footnotetext{
7 Disponível em: https://hora1rondonia.com.br/2019/03/02/lula-vetou-em-2010-vacina-parameningite-doenca-que-matou-seu-neto-de-7-anos/. Acesso em 24 mar. 2021.

${ }^{8}$ Disponível em: https://www.plantaobrasil.net/news.asp?nID=103403. Acesso em 22 mar. 2021.

9 Disponível em: https://curasnaturais.net/trump-alerta-a-vacina-da-gripe-e-a-maior-fraude-nahistoria-da-medicina/. Acesso em 22 mar. 2021.

${ }^{10}$ Disponível em: https://noticias.uol.com.br/colunas/jamil-chade/2020/05/04/brasil-fica-defora-de-acao-mundial-para-acelerar-vacina-e-apoiar-oms.htm. Acesso em 22 mar. 2021.

${ }^{11}$ Disponível em: https://g1.globo.com/sp/sorocaba-jundiai/noticia/2020/10/21/ja-mandeicancelar-diz-bolsonaro-sobre-protocolo-de-intencoes-de-vacina-do-instituto-butantan-emparceria-com-farmaceutica-chinesa.ghtml. Acesso em 22 mar. 2021.

${ }^{12}$ Disponível em: https://pleno.news/brasil/paulistas-se-recusam-a-tomar-vacina-da-chinacontra-covid.html. Acesso em 22 mar. 2021.
} 
aos conteúdos classificados efetivamente como desinformação. A resistência à Coronavac é verificada em falas de Bolsonaro e de outros agentes políticos, como "'Se a vacina é tão boa assim, começa aplicando na China', diz Russomanno" (O Globo) ) $^{13} \mathrm{e}$ "Janaina sobre a vacina chinesa: 'Por qual razão os testes não serão feitos na China. Não queremos ser cobaias"” (Gazeta Brasil) ${ }^{14}$.

Ainda quando presentes em conteúdos verificados, já que muitas das matérias se preocupam em desmentir essas falas a partir de evidências científicas, não se pode desmerecer o potencial da circulação dessas declarações para a desordem informativa. Nas redes sociais, é comum a recirculação de conteúdos apenas com a leitura do título, principalmente quando ele confirma visões prévias (Zago, Silva 2014). Portanto, em um contexto infodêmico, quando lideranças políticas refutam a ciência, a própria repercussão desses atos afeta as dinâmicas de circulação de desinformação (Oliveira 2020). Essa instrumentalização do debate em uma disputa discursiva política tem ainda como consequência a desvinculação da vacinação do campo das evidências científicas (Recuero, Soares 2021): ainda que a eficácia e a segurança da Coronavac tenham sido comprovadas, o imunizante passa a ser julgado a partir de afiliações políticas.

\section{DESINFORMAÇÃO E LÓGICAS PRODUTIVAS DA REDE}

Em um primeiro olhar, a comparação entre 2018-2019 e 2020 demonstra que a infodemia de COVID-19 não teria provocado um aumento da proporção de conteúdos desinformativos sobre vacinas. Além disso, o ecossistema informacional analisado continuaria a apresentar percentuais semelhantes de veículos profissionais e não profissionais. No entanto, uma análise mais atenta revela rupturas importantes para o estudo da desordem informativa no contexto infodêmico.

Em 2020, a média de engajamento da desinformação se tornou maior do que a dos conteúdos verificados, o que sugere um maior potencial de viralização durante a pandemia. Assim, ainda que presentes em menor escala, esses conteúdos alcançaram mais visibilidade, contribuindo exponencialmente para o aumento da desordem informativa. Esses dados corroboram estudo anterior que observou que a desinformação tem $70 \%$ mais chance de ser compartilhada no Twitter e que esses conteúdos circulam seis vezes mais rápido do que informações verificadas (Vosoughi et al. 2018).

Além disso, a mudança do perfil de desinformação aponta para uma complexificação do cenário infodêmico. Em 2018-2019, predominava o conteúdo fabricado, com posicionamento antivacina e emitido por veículos não profissionais. A informação falsa mais presente — replicada por seis veículos não profissionais - era a de uma

${ }^{13}$ Celso Russomanno (Republicanos/SP) é deputado federal e foi candidato à prefeitura de São Paulo em 2020. Disponível em: https://oglobo.globo.com/brasil/eleicoes-2020/se-vacina-taoboa-assim-comeca-aplicando-na-china-diz-russomanno-1-24726420. Acesso em 22 mar. 2021. 14 Janaina Paschoal (PSL/SP) é deputada estadual. Disponível em: https://gazetabrasil.com.br/politica/janaina-sobre-a-vacina-chinesa-por-qual-razao-os-testesnao-serao-feitos-na-china-nao-queremos-ser-cobaias/. Acesso em 22 mar. 2021. 
adolescente que teria engravidado após tomar a vacina da gripe, informação referendada por uma suposta "doutoranda em gravidez vacinal" (Massarani et al. 2020a). Já no contexto da pandemia, observamos uma predominância da conexão falsa, pró-vacina e emitida por veículos profissionais.

Enquanto os conteúdos fabricados remetem a informações totalmente falsas, as conexões falsas se referem a casos em que títulos trazem informações diferentes do restante do conteúdo, construídos muitas vezes de maneira sensacionalista, podendo levar o usuário a interpretações erradas. É O caso de "FIM DO CORONAVÍRUS: Vacina contra Covid-19 tem resultado positivo na fase inicial do ensaio clínico" (Yeereader) ${ }^{15}$. O vídeo traz informações verificadas, mas relaciona esses dados ao fim da pandemia, o que não é verdade. O mesmo ocorre em "Acabou a Farra! Boa Notícia: Vacina que será concedida ao SUS mostra bons resultados nos testes e pode acabar com Coronavírus e determinar a cura!"”6 (Yeereader).

Nesses conteúdos, recursos como o uso de caps lock e frases exclamativas aparentam ter o objetivo de atrair o clique do usuário. Na lógica econômica das redes, page views significam mais engajamento, convertido em ganhos financeiros para os veículos (Kischinhevsky, Fraga 2020). Portanto, esse ecossistema midiático favorece a proliferação de caça-cliques, conteúdos cujo principal objetivo é atrair a atenção do visitante e incentivá-lo a clicar em um link. As manchetes caça-cliques contribuem significativamente para a dispersão de desinformação (Chen et al. 2015), uma vez que, como já discutimos, o consumo e a recirculação do conteúdo frequentemente ocorrem apenas com a leitura do título (Zago, Silva 2014).

Nesses exemplos, veículos não profissionais foram os emissores. No entanto, a predominância da conexão falsa se relaciona diretamente ao aumento dos veículos profissionais na emissão de desinformação. As empresas de comunicação dependem cada vez mais de receitas publicitárias baseadas em métricas de engajamento. Esse fator tem alterado as rotinas jornalísticas, influenciando em decisões editoriais (Chen et al. 2015; Nguyen 2016). A lógica concorrencial das redes faz com que cada conteúdo jornalístico dispute visualizações com outras notícias e com outros conteúdos que não obedecem aos critérios jornalísticos (Bazaco et al. 2019), favorecendo o uso de manchetes exageradas e sensacionalistas, que podem funcionar como motores de desinformação.

Um exemplo de conexão falsa encontrado no corpus de 2020 que exemplifica os riscos desse cenário é “Enfermeira-chefe desmaia 'ao vivo' após tomar vacina contra Covid19"17 (Extra). Enquanto o título indica que o desmaio teria ocorrido em decorrência da vacinação, a matéria explica que não houve uma reação alérgica ao imunizante e que a enfermeira tinha uma condição médica que a faz desmaiar quando sente dor. Em um

\footnotetext{
${ }^{15}$ Disponível em: http://br.yeereader.com/home/watch?id=1048333. Acesso em 24 mar. 2021.

${ }^{16}$ Disponível em: http://br.yeereader.com/home/watch?id=1067019. Acesso em 24 mar. 2021.

17 Disponível em: https://extra.globo.com/noticias/page-not-found/enfermeira-chefe-desmaiaao-vivo-apos-tomar-vacina-contra-covid-19-24803342.html. Acesso em 23 mar. 2021.
} 
contexto cultural de circulação de discursos antivacina, um título como esse pode levar a uma compreensão errônea sobre a segurança dos imunizantes, sem que o restante da matéria seja acessado para esclarecer a situação. Esse título pode ir ao encontro de crenças prévias que reforcem a hesitação vacinal, aumentando também as chances de que ele seja compartilhado, contribuindo para a desordem informativa.

\section{CONSIDERAÇÕES FINAIS}

A comparação entre os links sobre vacina de maior engajamento em 2018-2019 e em 2020 revelou dados importantes tanto para compreender problemas persistentes na circulação de informação sobre a vacinação em redes sociais quanto para identificar desafios pertinentes à infodemia de COVID-19. O engajamento médio por link aumentou 8,6 vezes, reforçando um aumento significativo da importância da imunização nos debates públicos. A instrumentalização política do debate sobre vacinação, já presente em 2018-2019, manifesta-se em 2020 principalmente a partir do engajamento em torno da Coronavac. Líder entre os conteúdos desinformativos, a chamada "vacina chinesa" teve sua segurança questionada não por critérios científicos, mas por oposição ideológica baseada em questões políticas.

A predominância de informações verificadas, fontes profissionais e posicionamento favorável sobre a vacinação se manteve nos dois contextos. No entanto, a média de engajamento da desinformação passou a ser maior do que a das informações verificadas em 2020, confirmando que a infodemia favorece a proliferação desse tipo de conteúdo. Mudanças no perfil da desinformação também apontam para desafios contemporâneos na contenção desse cenário. Em 2018-2019, predominavam os conteúdos fabricados, antivacina e emitidos por veículos não profissionais. Já em 2020, a maior parte da desinformação se expressa em conexões falsas, pró-vacina e provenientes de veículos profissionais. Nesse aspecto, a lógica econômica das redes, ancorada em métricas de engajamento, atravessa a produção de conteúdos e favorece o aparecimento de manchetes caça-clique.

Esses resultados indicam a necessidade de não restringir o debate sobre a desinformação à intencionalidade e à qualidade das fontes (Oliveira 2020). Quando a prática de consumo e recirculação das informações se apoia frequentemente em uma leitura restrita ao título, conteúdos emitidos por veículos confiáveis e bem intencionados a veicular informações amparadas em evidências científicas podem, ainda assim, promover a desinformação, seja por manchetes sensacionalistas, seja pela mera veiculação de declarações de agentes políticos que questionem a segurança ou a eficácia das vacinas.

Portanto, se a atuação discursiva em rede do movimento antivacina configura uma clara ameaça à saúde pública, é preciso ir além desse âmbito e abordar a desinformação como um fenômeno complexo que, por vezes, assume contornos menos evidentes no debate público. Compreender os processos de circulação de informações nas redes sociais, considerando suas bases econômicas e suas relações 
com um contexto político mais amplo, pode fornecer subsídios para enfrentar esse cenário.

\section{FINANCIAMENTO}

Este estudo se insere no Instituto Nacional de Comunicação Pública da Ciência e Tecnologia (INCT-CPCT) e contou com recursos do Conselho Nacional de Desenvolvimento Científico e Tecnológico (CNPq), da Fundação de Amparo à Pesquisa do Estado do Rio de Janeiro (Faperj) e do Inova Fiocruz/Fundação Oswaldo Cruz.

\section{REFERÊNCIAS}

ALLCOTT, Hunt; GENTZKOW, Matthew. Social media and fake news in the 2016 election. Journal of Economic Perspectives, v. 31, n. 2, p. 211-236, 2017.

https://doi.org/10.1257/jep.31.2.211.

ALLCOTT, Hunt, GENTZKOW, Matthew; YU, Chuan. Trends in the diffusion of misinformation on social media. Research \& Politics, v. 6, n. 2, p. 1-8, 2019. https://doi.org/10.1177/2053168019848554.

ALSYOUF, Muhannad, STOKES, Phillip, HUR, Dan, AMASYALI, Akin, RUCKLE, Herbert; $\mathrm{HU}$, Brian. 'Fake News' in urology: evaluating the accuracy of articles shared on social media in genitourinary malignancies. BJU International, v. 124, n. 4, p. 701-706, 2019. https://doi.org/10.1111/bju.14787.

ARAUJO, Ronaldo Ferreira; OLIVEIRA, Thaiane Moreira de. Desinformação e mensagens sobre a hidroxicloroquina no Twitter: da pressão política à disputa científica. AtoZ, v. 9, n. 2, p. 196-205, 2020. Disponível em:

https://revistas.ufpr.br/atoz/article/view/75929/42144. Acesso em 24 mar. 2021.

BAZACO, Ángela, REDONDO, Marta e SÁNCHEZ-GARCíA, Pilar. Clickbait as a strategy of viral journalism: conceptualisation and methods. Revista Latina de Comunicación Social, v. 74, p. 94-115, 2019. Disponível em http://www.revistalatinacs.org/074paper/1323/06en.html. Acesso em 24 mar. 2021.

CANAVILHAS, João. El nuevo ecosistema mediático. index.Comunicación, v. 1, n. 1, p. 13-24, 2011. Disponível em:

https://journals.sfu.ca/indexcomunicacion/index.php/indexcomunicacion/article/view/ 4. Acesso em 10 jun. 2021.

CASTELFRANCHI, Yurij. Notícias falsas na ciência. Ciência Hoje, 2019. Disponível em https://cienciahoje.org.br/artigo/noticias-falsas-na-ciencia. Acesso em 15 mar. 2021.

CHEN, Yimin; CONROY, Niall J.; RUBIN, Victoria L. Misleading online content: recognizing clickbait as "false news". Em: WMDD '15: Proceedings of the 2015 ACM on 
Workshop on Multimodal Deception Detection, 2015.

http://dx.doi.org/10.1145/2823465.2823467.

CINELLI, Mateo; QUATTROCIOCCHI, Walter; GALEAZZI, Alessandro; VALENSISE, Carlo Michele; BRUGNOLI, Emanuele; SCHMIDT, Ana Lucia; ZOLA, Paola; ZOLLO, Fabiana; SCALA, Antonio. The COVID-19 social media infodemic. Scientific Reports, v. 10, n. 1, e16598, 2020. https://doi.org/10.1038/s41598-020-73510-5.

GALHARDI, Cláudia Pereira; FREIRE, Neyson Pinheiro; MINAYO, Maria Cecília de Souza; FAGUNDES, Maria Clara Marques. Fato ou Fake? Uma análise da desinformação frente à pandemia da Covid-19 no Brasil. Ciênc. saúde coletiva, v. 25, supl. 2, p. 4201-4210, 2020. https://doi.org/10.1590/1413-812320202510.2.28922020.

KATTA, Anna. Anti-vaccine activists, web 2.0, and the postmodern paradigm - an overview of tactics and tropes used online by the anti-vaccination movement. Vaccine, v. 30, n. 25, p. 3778-3789, 2012. https://doi.org/10.1016/j.vaccine.2011.11.112.

KENNEDY, Jonathan. Vaccine hesitancy: a growing concern. Pediatric drugs, v. 22, n. 2, p.105-111, 2020. Disponível em https://link.springer.com/article/10.1007/s40272-02000385-4. Acesso em 24 mar. 2021.

KISCHINHEVSKY, Marcelo; FRAGA, Renata. O jornalismo refém do algoritmo do Facebook: desafios regulatórios para a circulação de notícias numa sociedade de plataformas. Fronteiras, v. 22, n. 2, 2020. https://doi.org/10.4013/fem.2020.222.11.

MACHADO, Caio C. Vieira; SANTOS, João Guilherme; SANTOS, Nina; BANDEIRA, Luiza. Political (self) isolation: international trends in misinformation and the departure from the scientific debate. São Paulo: LAUT, 2020. Disponível em https://laut.org.br/wpcontent/uploads/2020/11/Political-Self-Isolation-vF.pdf. Acesso em 24 mar. 2021.

MASSARANI, Luisa; LEAL, Tatiane; WALTZ, Igor. O debate sobre vacinas em redes sociais: uma análise exploratória dos links com maior engajamento'. Cadernos de Saúde Pública, v. 36, supl. 2, p.1-13, 2020a. https://doi.org/10.1590/0102-311x00148319.

MASSARANI, Luisa; WALTZ, Igor, LEAL, Tatiane. COVID-19 in Brazil: an analysis about the consumption of information on social networks. Journal of Science Communication, v. 19, n. 7, p. 1-21, 2020b. https://doi.org/10.22323/2.19070207.

MENDONÇA, Ana Paula Bernardo; PEREIRA NETO, André. Critérios de avaliação da qualidade da informação em sites de saúde: uma proposta. Reciis, v.9, n.1, pp. 1-15, 2015. https://doi.org/10.29397/reciis.vgi1.930.

MONARI, Ana Carolina Pontalti, SANTOS, Allan e SACRAMENTO, Igor. COVID-19 and (hydroxy)chloroquine: a dispute over scientific truth during Bolsonaro's weekly Facebook live streams'. JCOM, v. 19, n. 7, A03, 2020.

https://doi.org/10.22323/2.19070203.

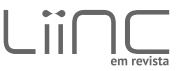


NGUYEN, An. O julgamento das notícias na cultura "caça-clique": o impacto das métricas sobre o jornalismo e sobre os jornalistas. Parágrafo, v.4, n.2, 2016. Disponível em http://revistaseletronicas.fiamfaam.br/index.php/recicofi/article/view/483. Acesso em 24 mar. 2021.

OLIVEIRA, Thaiane; MARTINS, Rodrigo Quinan Ribeiro; TOTH, Janderson Pereira. Antivacina, fosfoetanolamina e Mineral Miracle Solution (MMS): mapeamento de fake sciences ligadas à saúde no Facebook. Reciis, v. 14, n. 1, p. 90-111, 2020.

https://doi.org/10.29397/reciis.v1411.1988.

OLIVEIRA, Thaiane. Como enfrentar a desinformação científica? Desafios sociais, políticos e jurídicos intensificados no contexto da pandemia. Liinc em Revista, v. 16, n. 2, e5374, 2020. https://doi.org/10.18617/liinc.v16i2.5374.

OMS. Managing epidemics: key facts about major deadly diseases. Organização Mundial da Saúde, 2018. Disponível em:

https://www.who.int/emergencies/diseases/managing-epidemics-interactive.pdf. Acesso em: 15 março 2021.

OMS. Managing yellow fever epidemics. Organização Mundial da Saúde, 2019. Disponível em: https://www.who.int/emergencies/diseases/managing-epidemicsinteractive.pdf. Acesso em: 15 março 2021.

PARISER, Eli. O filtro invisível: o que a internet está escondendo de você. Rio de Janeiro: Zahar, 2012.

PAULA, Julia Ester; CAMILO, Lucas Perrone; SIQUEIRA, Ester Wagner. A corrida pela vacinação contra a Covid-19 no Brasil: como as fake news e o descaso do governo podem influenciar na imunização? Disponível em https://cjt.ufmg.br/2021/02/03/acorrida-pela-vacinacao-contra-a-covid-19-no-brasil-como-as-fake-news-e-o-descaso-dogoverno-podem-influenciar-na-imunizacao/. Acesso em 24 mar. 2021.

HERNÁNDEZ, Jonathan. Desinformación y crisis sanitaria: alcances y oportunidades para las bibliotecas. Biblioteca Universitaria, v. 23, n. 1, pp. 110-118, 2020. https://doi.org/10.22201/dgb.0187750xp.0.0.991. Acesso em 9 jun. 2021.

POELL, Thomas; NIEBORG, David; VAN DIJCK, José. Plataformização. Fronteiras, v. 22, n. 1, p. 2-10, 2020. https://doi.org/10.4013/fem.2020.221.01.

RECUERO, Raquel; SOARES Felipe Bonow. O discurso desinformativo sobre a cura do COVID-19 no Twitter: estudo de caso. E-compós, 2021.

https://doi.org/10.30962/ec.2127.

RECUERO, Raquel; SOARES, Felipe; ZAGO, Gabriela. Polarization, hyperpartisanship and echo chambers: how the disinformation about Covid-19 circulates on Twitter. SciELO Preprints, 2020. https://doi.org/10.1590/SciELOPreprints.1154. 
SCHEUFELE, Dietram A.; KRAUSE, Nicole M. Science audiences, misinformation, and fake news. PNAS, v. 116, n. 16, p. 7662-7669, 2019.

https://www.pnas.org/content/116/16/7662. Acesso em 20 jan. 2020.

SILVA, Leila M.; LUCE, Bruno; SILVA FILHO, Rubens da Costa. Avaliação de critérios para fontes de informações na área da saúde no contexto da pós-verdade. Em: IV Encontro Regional dos Estudantes de Biblioteconomia, Documentação, Ciência e Gestão da Informação. Porto Alegre, RS: UFRGS, 2017. Disponível em https://lume.ufrgs.br/bitstream/handle/10183/157720/001021282.pdf. Acesso em 15 mar. 2021.

SOMMARIVA, Silvia; VAMOS, Cheryl; MANTZARLIS, Alexios; ĐÀO, Lillie Uyên-Loan; TYSON, Dinorah Martinez. Spreading the (fake) news: exploring health messages on social media and the implications for health professionals using a case study. American Journal of Health Education, v. 49, n. 4, p. 246-255, 2018. https://doi.org/10.1080/19325037.2018.1473178.

TANDOC Jr, Edson; LIM, Zheng; LING, Rich. Defining 'Fake News': A typology of scholarly definitions. Digital Journalism, v.1, n.17, p. 137-153, 2017. https://doi.org/10.1080/21670811.2017.1360143.

VIEIRA, Livia; CHRISTOFOLETTI, Rogério. Métricas, ética e 'cultura do clique’ no jornalismo online brasileiro: o caso de resistência do não fo.de. Dispositiva, v. 1, n.3; Estudos de Jornalismo, v. 1, n.5, 2015. https://doi.org/10.5752/P.2237-9967.2015v4n1p7487.

VOSOUGHI, Soroush; ROY, Deb; ARAL, Sinan. The spread of true and false news online. Science, v. 359, n. 6380, p. 1146-1151, 2018.

https://doi.org/10.1126/science.aap9559.

WALTZ, Igor. Startups Jornalísticas: Inovações e continuidades no jornalismo brasileiro do século XXI. Tese (Doutorado em Comunicação e Cultura). Rio de Janeiro, RJ: Universidade Federal do Rio de Janeiro, 2019. Disponível em: http://www.pos.eco.ufrj.br/site/teses_dissertacoes_interna.php?tease=20.

WARDLE, Claire, DERAKHSHAN, Hossein. Information disorder: toward an interdisciplinary framework for research and policymaking. Estrasburgo: Conselho da Europa, 2017. https://rm.coe.int/information-disorder-toward-an-interdisciplinaryframework-for-researc/ 168076277c. Acesso em 1 dez. 2018.

WASZAK, Przemyslaw M., KASPRZYCKA-WASZAK, Wioleta; KUBANEK, Alicja. The spread of medical fake news in social media - the pilot quantitative study. Health Policy and Technology, v. 7, n. 2, p. 115-118, 2018. https://doi.org/10.1016/j.hlpt.2018.03.002.

ZAGO, Gabriela da Silva; SILVA, Ana Lúcia Migowski da. Sites de rede social e economia da atenção: circulação e consumo de informações no Facebook e no 
Twitter. Vozes e Diálogo, v. 13, n. 1, 2014. Disponível em:

https://www6.univali.br/seer/index.php/vd/article/view/530. Acesso em 24 março 2021.

ZORZETTO, Ricardo. As razões da queda na vacinação: ao menos nove fatores contribuem para a redução na imunização infantil e aumentam o risco de doenças graves ressurgirem. Pesquisa Fapesp, ed. 270, 2018. Disponível em https://revistapesquisa.fapesp.br/as-razoes-da-queda-na-vacinacao/. Acesso em 24 mar. 2021. 